\title{
LA DESPATRIMONIALIZACION DEL AGUA: MOVILIZACION DE UN RECURSO NATURAL FUNDAMENTAL *
}

\author{
JORDI MALUQUER DE MOTES \\ Universidad Autónoma de Barcelona
}

El objetivo de la presente comunicación consiste en precisar los diversos modos en que el agua, recurso económico fundamental, resultó afectada por el proceso de modernización que implicaba la labor revolucionaria antifeudal del siglo xIX y las consecuencias que de ello se derivaron. Para conseguir esta meta será necesario definir brevemente el régimen feudal de propiedad de las aguas y justificar el significado del neologismo despatrimonialización, que me he tomado la libertad de acuñar. Trazo general de las soluciones que dio la revolución liberal a los problemas de las formas de propiedad típicas del antiguo régimen es su carácter negativo, es decir, la eliminación de los factores que la hacían inmovilizada, amortizada o vinculada. Como la tierra, tampoco las aguas tenían, en la etapa de predominio del sistema feudal, la condición de bienes libres de propiedad particular. El mencionado carácter negativo está en la base, incluso en su misma construcción gramatical, de los términos castellanos desamortización y desvinculación ${ }^{1}$. Esta es una de las razones por las que me he decidido a emplear, en el caso del agua, el término despatrimonialización. He elegido también, y principalmente, esta expresión porque integra muy bien, en su parte positiva, las distintas situaciones que se dan respecto de la propiedad del agua en la sociedad feudal.

\section{La condición patrimonial del agua}

A diferencia de la Europa búmeda, central y noroccidental, en la que la cantidad de agua contenida en el suelo resultaba excesiva para su adecuado

- La presente comunicación constituye un resumen del texto presentado en el "Colóquio sobre o Liberalismo na Peninsula na Primeira Metade do Séc. XIX" celebrado en Lisboa, del 11 al 13 de febrero de 1981, a iniciativa del Centro de Estudos de Histórica Contemporânea Portuguesa.

1 Gumersindo DE AzcARAtE, Ensayo sobre la historia del derecho de propiedad y su estado actual en Europa, Madrid, 1879-1883, vol. II, pp. 381-382. 
cultivo $^{2}$, en la Europa seca, mediterránea, las corrientes de agua y la tecnología de su conducción y distribución alcanzaban un elevado valor a causa de la irregularidad de las lluvias, casi siempre concentradas de forma torrencial en breves períodos de tiempo, y de una activísima evaporación. El déficit, mayor o menor, en la alimentación hídrica de los vegetales de las comarcas áridas o semiáridas de la cuenca mediterránea sólo podía ser compensado con el riego, hasta el punto que, en algunos lugares, la tierra sin riego tenía un valor económico prácticamente nulo, mientras que producía dos cosechas al año si se le proporcionaba suficiente volumen de agua.

Pero el agua, gratuita cuando cae sobre el suelo en adecuada cantidad y con la regularidad deseada, resulta a un precio elevado, a veces muy elevado, cuando se adiciona artificialmente a la tierra. Como afirmara Jovellanos, «el riego artificial es dispendioso, porque se compra; nadie le goza sin recompensar al propietario de las aguas, y esta recompensa es tanto más justa, cuanto la propiedad es más costosa» ${ }^{3}$.

Salvo en el caso de tierras ribereñas que puedan sujetarse a irrigación con derivaciones muy simples, el regadío determina costes fijos muy elevados para los campesinos. Y, además, lo que tiene mucha mayor importancia, son en buena parte costes que, por iniciales, corresponden a gastos necesarios para empezar a producir. Es decir, se precisa de una fuerte inversión previa. Pero no reside ahí solamente la dificultad, sino que, por otra parte, son también costes generales que muy difícilmente pueden asignarse a unidades de producción concretas. Por todo ello, cuando se realizan nuevas obras de irrigación en el marco de la sociedad feudal, sobre todo en los grandes sistemas hidráulicos mediterráneos, el dominio señorial es prácticamente inevitable. En definitiva, cuando se trataba de sistemas hidráulicos de gran envergadura la iniciativa sólo podía partir de elementos capaces de movilizar considerables recursos $y$, también, de ejercer una coacción eficaz con el fin de imponer servidumbres, obligar al uso del agua y asegurar la rentabilidad de las inversiones realizadas. En las condiciones apuntadas, las decisiones sólo podían ser tomadas de forma centralizada por parte de los señores feudales y, excepcionalmente, de instituciones municipales ya muy desarrolladas.

En cambio, cuando se trataba de la ocupación y aprovechamiento de sistemas ya establecidos y de la creación de redes nuevas proporcionalmente

\footnotetext{
${ }^{2}$ Las obras de drenaje y desecación y, sobre todo, la acción del arado de vertedera permitieron, entre los siglos XI y XIII, aumentar la superficie cultivada $y$ elevar los rendimientos. Marc BLoch, La historia rural francesa. Barcelona, 1978, páginas 150-156; Lynn WHITE, Jr., Technologie médiévale et transformations sociales, Paris, 1968, pp. 57-68.

${ }^{3}$ Gaspar Melchor de Jovellanos, Informe de la Sociedad Económica de Madrid al Real y Supremo Consejo de Castilla en el expediente de Ley Agraria, en Obras escogidas, Barcelona, 1885, vol. II, p. 188.
} 
reducidas, o bien de la ampliación de regadíos en funcionamiento, sí cabía la iniciativa de los usuarios. En estos casos, sin embargo, hacía falta normalmente la intervención de una entidad capaz de allegar recursos y aplicarlos al objetivo perseguido, asegurar el mantenimiento del utillaje técnico de la irrigación y obligar a los potenciales consumidores del riego a emplear el sistema y, en consecuencia, a rentabilizar la inversión. Tales entidades solían ser los propios pueblos, bien directamente como comunidad de vecinos, bien indirectamente como universitas o municipio.

Un segundo aprovechamiento hidráulico practicado a gran escala, tanto en la Europa húmeda como en la Europa seca, fue el de la fuerza motriz generada por el movimiento y el peso del agua, a través de los molinos harineros o de los dedicados a multitud de actividades agrarias y manufactureras. Otros aprovechamientos, alrededor de los cuales se creaban derechos de propiedad, fueron el transporte mediante la navegación y la flotación y el de la pesca.

El agua tenía, en resumen, una gran importancia en la sociedad feudal, desde el momento en que daba pie a una serie de aprovechamientos altamente productivos en los aspectos agrícola, industrial, de transportes y piscícola. Aún podía proporcionar ingresos en función de otros servicios (aprovisionamiento de poblaciones, ciertas utilizaciones industriales como la tintorería, paso de personas y cosas mediante barcas o puentes, etc.). Interesa, por consiguiente, establecer cuál fue su naturaleza jurídica a la vista de sus utilizaciones y de su valor económico.

Las aguas tuvieron siempre, en la Europa feudal, la consideración de bienes personales o patrimoniales. Desde los primeros siglos medievales aparecen como pertenencias sujetas al dominio eminente del soberano y, en consecuencia, al derecho de disponer por parte del mismo ${ }^{4}$. Como tal pertenencia del poder regio podían ser objeto de cesión, donación o alienación de dominio, a título de derecho privado, en beneficio de señores, monasterios, abadías u otras entidades que alcanzaban, por tanto, plena capacidad de decisión sobre ellas. Así, los señores feudales asumieron, por acciones de traslación parcial de la soberanía, derechos hereditarios de carácter dominical o patrimonial sobre las aguas. Pero siempre con reserva de uso.

La división de dominios propia del régimen feudal de propiedad se materializaba también en el ámbito hidráulico, al igual que en el de la tierra, puesto que el derecho señorial de disponer era compatible y complementario del derecho de terceros a usar. La propiedad eminente de los señores coexistía con la propiedad útil de otros. Estos últimos, como propietarios, gozaban del

4 Jesús Lalnnde Abadí, "La consideración jurídica de las aguas en el derecho medieval hispánico", en Anales de la Universidad de La Laguna, vol. VI (1969), páginas 1-51. Véanse las pp. 5-8. 
agua de forma gratuita y perpetua, aunque limitada al uso y privada de la capacidad de disponer. Con mucha frecuencia, los dueños útiles del agua, plenos beneficiarios de su aprovechamiento, no eran particulares, sino comunidades, aldeas o pueblos. Como ha señalado Nieto para la tierra, también en lo que se refiere al agua «el elemento comunal se inserta dentro del señcrial» ${ }^{5}$. De hecho, las aguas comunales procedían, en su mayor parte, de concesión señorial o real de los términos territoriales con las pertenencias de pastos, bosques y aguas a las comunidades allí establecidas mediante cartas de población y franquicias o privilegios especiales ${ }^{6}$. Por la naturaleza misma de los aprovechamientos, en bastantes circunstancias el dominio útil comunal era objeto de cesión a los particulares. En tales ocasiones, no obstante, la comunidad conservaba la titularidad del dominio útil por encima de los usuarios. La gratuidad del uso comunal del agua no parece haber conocido excepciones. Por ello, el acceso individual y excluyente a la propiedad útil por los vecinos, a costa de las aguas comunales, no se efectuaba a título oneroso, sino mediante presura o aprisión. Es decir, por señalamiento de apropiación y ocupación efectiva de las aguas.

Por consiguiente, además de los derechos del soberano, de los señores y los pueblos, que podían ejercerse simultáneamente, se formó por debajo de todos ellos un cuarto tipo de propiedad, la individual o correspondiente a vecinos particulares. También es cierto, sin embargo, que, aparte de lo comunal y de lo individual de tales aguas, ciertos aprovechamientos, singularmente el molino y la pesca, adquirieron un carácter derivado y nuevo. Sin distinguirse absolutamente de las comunales, las aguas sujetas a esos aprovechamientos quedaron afectadas a los municipios como tales y, consiguientemente, sujetas a apropiación excluyente de los mismos. Puede hablarse entonces de aguas patrimoniales de los municipios o de propios, por más que otros usos de las mismas siguieran siendo comunales o incluso particulares.

Los aprovechamientos hidráulicos fueron hechos también, en muchos casos, directamente por individuos singulares. En determinadas circunstancias, los propios señores retuvieron el dominio útil de las aguas junto al eminente que les correspondía por razón de señorío, mientras que otras veces cedieron este mismo dominio útil a terceros a través de diversos procedimientos, que cabe clasificar en cuatro modalidades: 1) la enajenación del dominio, 2) la enajenación del disfrute, 3) la enfiteusis, y 4) el repartimiento.

El régimen feudal del agua en la sociedad preindustrial era, pues, enormemente complejo y dispar. El dominio eminente correspondía al soberano,

\footnotetext{
5 Alejandro NIETo, Bienes comunales, Madrid, 1964, pp. 55-56, nota 58.

- J. M.' Font Rfus, Origenes del régimen municipal de Cataluña, Madrid, 1946 , p. 178.
} 
pero también a los señores feudales e incluso a las comunidades municipales. El dominio útil podía ser retenido por los propios dueños eminentes o, más bien, cedido a los pueblos, con lo que las aguas quedaban convertidas, a efectos de uso, en bienes comunales. En este último caso podían mantenerse como bienes comunes puros, de todos los miembros del común, o transformarse en propios del municipio y aun en personales de los vecinos, que accedían a ellos por presura o por adquisición. También podían ser cedidas a particulares directamente mediante enajenación de dominio eminente o de dominio útil, enfiteusis o donación. Así, las aguas de un mismo término podían ser, a la vez, del rey - con dominio eminente que me atrevo a calificar de «mayor»-, de uno o varios señores - con dominio eminente subordinado o «menor»-, del común de los vecinos, del municipio y de los mismos vecinos individualmente. Cualquiera de los titulares de propiedad, eminente o útil, podía arrendar, donar, ceder o enajenar sus derechos contiguos a terceros. Todo ello configura un confuso panorama de sobreposición de derechos.

Desde la Baja Edad Media, la evolución del derecho, bajo influencia romanista, modificó todo el régimen socioeconómico del agua, a causa de la cada vez mayor importancia de las atribuciones del soberano. La doctrina regalista, que entiende "regalía» como derecho reservado al rey sin sumisión del mismo a fin alguno ${ }^{7}$, en cuanto que se aplicó a las aguas, determinó la creciente retracción de los dominios eminentes particulares. Pero esto no significó una transformación fundamental en el régimen socioeconómico de las aguas, puesto que siguieron formando res in patrimonio, aunque se tratara del perteneciente al monarca, y no res in publico usu. La concepción patrimonial seguía plenamente vigente. La patrimonialización de las aguas comportaba la plena capacidad de los dueños eminentes de reservarse percepciones diversas, a su libre arbitrio, y recaudar tributos para consentir el uso a terceros.

El régimen feudal de patrimonialización de las aguas dificultaba el desarrollo de la práctica totalidad de las actividades productivas, puesto que en casi todas ellas intervenía el agua como factor de producción, con un coste específico que debía sumarse a los demás costes. Constituía, en este sentido, un importante obstáculo al crecimiento económico. En Cataluña, País Valenciano e Islas Baleares, la mayor accesibilidad de las aguas del Real Patrimonio, frente a las más rígidamente condicionadas por la arbitraria voluntad de los señores en el resto de los reinos hispánicos, y la seguridad en el disfrute que da la enfiteusis, pudieron ser factores que contribuyeron a multiplicar su aprovecamiento productivo ${ }^{8}$.

7 J. Lalinde Abadia, op. cit., p. 31.

- Cirilo Franquet y Bertrán, Ensayo sobre el origen, espíritu y progresos de la legislación de Aguas, Madrid, 1864, vol. I, p. 102. 


\section{La legislación despatrimonializadora}

La demanda de agua aumentó rápidamente y de forma progresivamente acelerada a lo largo del siglo xviII en el conjunto de la Europa occidental, y singularmente en el área mediterránea. Las transformaciones de las fuerzas productivas que impulsaron el arranque del proceso de industrialización estaban basadas, justamente, en la multiplicación de la cantidad e intensidad de los usos del agua, incluso en la propia Gran Bretaña ${ }^{9}$. Al mismo tiempo, la creciente urbanización, resultado del masivo desplazamiento de grandes contingentes de población activa desde el sector primario hacia el secundario y desde el campo a la ciudad, aumentó la demanda para aprovisionamientos urbanos. También acrecentó la necesidad de elevar la productividad de los agricultores, para suministrar alimentos a los ciudadanos en cantidades cada vez mayores y para liberar brazos con destino a las fábricas y los servicios, lo que exigía mayores cantidades de agua. La máquina de vapor, finalmente, requería, asimismo, de suministros regulares de agua, tanto si se trataba de máquinas fijas como locomóviles. Pierre Vilar ha expuesto, en unas páginas magistrales, la auténtica «fiebre del agua» que se produjo en la Cataluña del XVIII ${ }^{10}$.

La respuesta a esta nueva situación, que evidenciaba las rigideces del sistema tradicional del agua, se había de producir en dos fases bien diferenciadas. En una primera secuencia, los gobernantes ilustrados trataron de aplicar soluciones reformistas, promoviendo el aumento de los aprovechamientos productivos del agua, pero respetando a la vez el viejo régimen de propiedad y la antigua patrimonialización. A ese planteamiento, en la línea de estimular a los funcionarios a incitar a los particulares a ampliar los regadíos, responde la Instrucción de Corregidores de 15 de mayo de $1788^{11}$.

La segunda secuencia de la respuesta a la nueva situación de escasez relativa de agua, protagonizada ahora por los liberales, tendría un carácter distinto, plenamente revolucionario. El primer paso corresponde al Decreto francés de 4 de agosto de 1789 que abolió los derechos dominicales sobre las aguas. El artículo 598 del Código Civil convertía en bienes de dominio público los cursos de agua navegables y flotables, y consolidaba los derechos comunales de los ribereños sobre las aguas que no tenían las características apuntadas. En gran parte de Italia, el impacto de las leyes francesas fue

\footnotetext{
- A. E. Musson y E. Robinson, Science and Tecnology in the Industrial Revolution, Manchester, 1969, pp. 67-72.

10 Pierre VIlaR, Catalunya dins l'Espanya moderna. Recerques sobre els fonaments econòmics de les estructures nacionals, Barcelona, 1964-1968, vol. III, páginas 259-317.

"Joaquín Escriche, Diccionario razonado de legislación y jurisprudencia, Madrid, 1874, vol. I, p. 211.
} 
directo, con lo que las ciudades resultaton privadas de la jurisdicción que venían ejerciendo sobre las aguas de sus términos. El Código Civil de Parma especificaba la condición de dominio público de las aguas navegables y flotables ${ }^{12}$. En el reino de Nápoles el Decreto de José Bonaparte del 2 de agosto de 1806 establecía la abolición de los derechos feudales sobre las aguas y declaraba la propiedad pública de los ríos. De todos modos, la fragmentación de la península impidió que estos cambios quedaran perfectamente formulados hasta la promulgación del Código Civil italiano en 1865. En Portugal, el Decreto de 13 de agosto de 1832 convertía las aguas de los ríos navegables en bienes públicos o de la nación entera ${ }^{13}$.

En España, la abolición de la condición patrimonial del agua se realizó a través de dos Decretos de las Cortes de Cádiz, de 6 de agosto de 1811 y de 19 de julio de 1813, respectivamente. Por el primero quedaba suprimido el dominio eminente de los señores sobre las aguas de particulares y éstas pasaban a ser de dominio general. Por el segundo se extendía esta provisión a las aguas sujetas al Real Patrimonio, fundamentalmente las de Cataluña, País Valenciano e Islas Baleares ${ }^{14}$. De este modo, los titulares del dominio útil recibían automáticamente el dominio directo $\mathrm{y}$, por lo mismo, quedaban liberados del pago de censos enfitéuticos, laudemio y fadiga.

Son perfectamente conocidas las vicisitudes de la legislación revolucionaria en materia de señoríos, con el restablecimiento de los mismos en 1814 y 1823 y su también doble abolición en 1820 y en 1837 . Pero es mucho menos sabido el hecho de que en la reintegración de los señoríos se establecía, mediante la Real Cédula de 15 de septiembre de 1814, la excepción de las rentas o censos que tuvieran «notoriamente su origen de la jurisdicción y privilegios exclusivos» ${ }^{15}$. El significado de la disposición real es, en este punto, perfectamente claro: cualquiera podía proceder al aprovechamiento de las aguas sin necesidad de alcanzar autorización o establecimiento oneroso de los señores jurisdiccionales, a la vez que quedaban convertidos en plenos propietarios todos los titulares del dominio útil de algún aprovechamiento. Las aguas quedaban configuradas como un bien a cuya utilización la ley reconocía un derecho igual para todos.

En el propio articulado de esta última disposición, sin embargo, se reconocía expresamente una importantísima excepción: la facultad exclusiva del

12 Bernardo Barbirluni Ammer, La nature publique et privée des eaux en droit italien, Roma, 1933, pp. 34-47; Luis Jordana dE Pozas, "La evolución del derecho de aguas en España y en otros países", en Revista de Administración Pública, 37 (enero-abril de 1962), pp. 9-61. Véanse las pp. 31 y 32.

13 Guilherme Alves Morern, As águas no direito civil português, Coimbra, $1960^{2}$, p. 13, nota 1.

14 C. Franquet y Bertrán, op. cit., vol. II, pp. 225-229.

is Decretos del Rey Don Fernando VII, Madrid, 1818, vol. I (1814), p. 253. 
Real Patrimonio allí donde existiere; es decir, en Cataluña, Valencia y las Baleares. Aquí el agua seguía siendo un bien sujeto al dominio irrenunciable del rey, y los particulares, para disponer del derecho a usarlo, debían aceptar en todo caso las condiciones que aquél quisiera exigir.

La discriminación no podía ser más clara ni más hiriente. Buena prueba de la irritación general que levantaba el mantenimiento del régimen patrimonial del agua, particularmente en Cataluña, por las peculiaridades del régimen enfitéutico - que establecía un laudemio de un tercio del valor de la cosa vendida ${ }^{16}$-, es el texto de la petición que 42 miembros del Estamento de Procuradores firmaron a 21 de octubre de 1834 y presentaron al organismo de que formaban parte solicitando la abolición de los privilegios del Real Patrimonio en esta materia. Dicho manifiesto contaba con las firmas de los procuradores catalanes, entre los que destacan algunos de los más notables miembros de la burguesía comercial e industrial, como Ramón de Llano y Chávarri, Pablo Torrens y Miralda, José Camps y Soler, Ramón de Siscar, José Viñals, Honorato de Puig o Joaquín Fleix, y con las de notorios dirigentes de la izquierda liberal, como Joaquín María López, Javier de Ulloa, Pablo Heredia y el conde de las Navas. En su parte final reclamaba la libertad absoluta para los aprovechamientos hidráulicos y la conversión de los derechos de los enfiteutas en plena propiedad ${ }^{17}$.

Tal discriminación se mantuvo hasta que, tras la crisis revolucionaria del verano de 1835, el Gobierno de Mendizábal puso fin a los privilegios del Real Patrimonio. En efecto, el Real Decreto de 19 de noviembre de 1835 disponía la exención del pago de toda clase de derechos por el uso del agua y la libertad de utilización de la misma con arreglo a las normas generales existentes sobre la cuestión. Mediante esta disposición se concedía «la libre facultad de construir molinos de harina, de papel, de aceite, batanes, barcas de pasaje y demás ingenios y artefactos, (...) abrir catas y hacer zanjas para buscar aguas subterráneas y utilizarse de las propias, y abrir pozos» ${ }^{18}$. Se conservaba todavía, sin embargo, la exigencia del laudemio, aunque reducido al canon fijo del 2 por 100 . Esta percepción residual desapareció poco después, a comienzos del año 1837, al restablecerse definitivamente los Decretos de las Cortes de Cádiz contra los derechos dominicales de los señores

16 Ramón LÁzaro DE Dou, Proyecto sobre laudemios, Cervera, 1829, pp. 39-41.

17 "Un catalán amante de su país": Manifestación de las justas razones en que se apoya la petición que cuarenta y dos Sres. Procuradores del Reino han presentado a su Estamento para que la eleve a $S$. $M$. suplicándole se sirva permitir a los naturales y habitantes de las provincias de la Corona de Aragón el construir molinos y hornos, $y$ utilizarse de las aguas con arreglo a las leyes sin necesidad de obtener establecimiento del Real Patrimonio, aboliendo su actual administración y juzgados, Barcelona, 1835, pp. 3-7.

18 Decretos de la Reina Nuestra Señora Doña Isabel II, Madrid, 1836, vol. XX (1835), pp. 540-541; C. Franquet y Bertrán, op. cit., pp. 246-247. 
y del rey por parte del Gobierno de José María Calatrava ${ }^{19}$. De este modo quedaba concluida la legislación despatrimonializadora de la revolución. En virtud de este conjunto de disposiciones, las aguas perdían las cargas de naturaleza feudal que pesaban sobre ellas y las vinculaciones que las atenazaban. Resta precisar cómo quedó regulado el acceso al uso de las aguas a partir de las leyes modernas.

\section{El moderno dominio del agua}

La despatrimonialización de las aguas constituyó una transformación de su régimen jurídico análoga y paralela a la que supuso para la tierra el bloque de medidas abolicionistas de señoríos y mayorazgos. Pero de la misma forma como la propiedad privada de la tierra no resultó erosionada, sino reforzada, del proceso de la revolución liberal, también la propiedad privada del agua experimentó una evidente consolidación. Utilizando las formulaciones típicas de los juristas postrevolucionarios y manteniendo el paralelismo hasta ahora observado entre tratamiento del agua y tratamiento de la tierra, se podría formular la conclusión de que a la propiedad «imperfecta», es decir, compartida e inmovilizada, le sustituye la propiedad «perfecta», o sea, individual, absoluta, libre y alienable.

Para examinar el sentido de aquellos cambios es preciso distinguir las aguas sujetas a previa apropiación de forma manifiesta de aquellas otras que no eran utilizadas ni tampoco podían atribuirse fácilmente a predios concretos por tratarse de aguas corrientes. En lo que atañe a la primera de estas clases, la legislación de aguas tuvo en el período revolucionario un claro carácter privatizador. Esto aparecía reflejado de forma diáfana en las disposiciones más arriba referidas a través de la confirmación de todos los dominios útiles preexistentes, sin excepción alguna, y su conversión en plena propiedad. Lo único que suprimían, también sin excepción, eran los dominios eminentes por razón de señorío o realengo. En consecuencia, las aguas sobre las que antes sólo se poseía un derecho de uso pasaron a ser objeto de apropiación absoluta y de aprovechamiento exclusivo, con la facultad de ser transferibles y alienables, del mismo modo que las demás cosas. Esto no debe entenderse como un simple resultado del reforzamiento de la propiedad privada de la tierra, puesto que quedaba, asimismo, subsistente y confirmado el dominio particular del agua cuando se ejercía independientemente del dominio del suelo.

Igualmente clara es la cabal aplicación que los legisladores liberales hicieron del principio privatizador en lo que se refiere a las aguas que caen,

19 Por leyes de 29 de enero y 2 de febrero de 1837. 
brotan o permanecen en tierra de particulares: quedaban definidas como pertenecientes siempre al dueño del terreno afectado, sin otra limitación que la de no causar perjuicio a terceros. También fueron declaradas de propiedad privada las aguas subterráneas que pudieran alumbrarse, desde el momento en que se reconoció explícitamente a los propietarios del suelo, en el anteriormente citado Real Decreto de 19 de noviembre de 1835, el derecho de extraer aguas por medio de pozos, minas, catas o zanjas. La nueva ley de 1866 otorgaba aún un plazo extraordinario de veinte años, a contar desde su promulgación, para hacer efectivos todos aquellos viejos derechos de aguas que no hubieran sido ejercidos por sus titulares ni siquiera parcialmente. También consolidaba a quienes durante veinte años o más hubiesen disfrutado aguas sin título ni autorización, siempre que no mediare oposición de la autoridad o de tercero.

En resumen, resultaron confirmados y reforzados todos los derechos de uso anteriores, incluidos los de quienes poseían agua exclusivamente, sin suelo alguno, y por ello no podían de hecho usarla, sino sólo venderla. Fueron privatizadas también todas las aguas pluviales, manantiales o estancadas que pudieran considerarse como adherencia de cada predio, hasta el momento en que, naturalmente, acabaran saliendo de los mismos. Idéntica consideración merecían, finalmente, las aguas subterráneas. En definitiva, como advirtiera Galán en 1849, «se observa una tendencia marcada a emancipar la propiedad de toda traba (...). A impulsos de esta legislación han desaparecido varios obstáculos que impedían sacar de las aguas todo el provecho que exige el interés general» ${ }^{20}$.

Es cierto que la naturaleza especial del agua dificulta o impide, en algunos casos, un disfrute absoluto, a diferencia de otros bienes susceptibles de apropiación privada. De esa circunstancia nacen una serie de limitaciones a la propiedad o determinadas servidumbres, es decir, ciertos derechos de personas o fincas sobre heredades ajenas que la ley reconoce. Pero en la práctica tales servidumbres no hacen más que completar la propiedad, o bien modificarla en beneficio del dominio de tercero, pero en ningún caso destruirla.

Un tratamiento distinto parece haberse aplicado a la segunda de las clases de agua que he distinguido, las no utilizadas ni fácilmente imputables a fincas concretas de titularidad determinada. En la medida en que habían resultado abolidos los derechos eminentes del rey, como individuo, y de los señores, así como de los pueblos, extendidos todos ellos sobre el conjunto de las aguas, fuera con utilización efectiva o sin ella, la titularidad de las aguas revertía a la nación.

Debe advertirse al respecto que las leyes revolucionarias no hacen defi-

${ }^{20}$ Francisco Galá, Tratado de legislación y jurisprudencia sobre aguas, Valencia, 1849, pp. vinI y $\mathbf{x x}$. 
nición expresa del dominio a que puedan atribuirse estas aguas, que podríamos llamar vacantes o nullius. Pero distintas providencias dictadas inmediatamente después las declaraban materia de concesión y jurisdicción administrativas, lo que implícitamente suponía su clasificación como bienes de patrimonio público ${ }^{21}$.

Podría argumentarse, a partir de este punto, de forma totalmente opuesta a como lo he venido haciendo en los párrafos precedentes. Es decir, apuntando a un proceso de nacionalización de las aguas como trasfondo de la legislación liberal. Esto sería, a mi entender, muy equivocado, puesto que también en el caso de las aguas declaradas de dominio público es perfectamente posible descubrir la impronta privatizadora. Varias consideraciones dan apoyo a este razonamiento.

Es verdad, en primer lugar, que el legislador mantuvo una permanente negativa a reconocer una forma preexistente de propiedad: la propiedad comunal de los ríos y otras corrientes permanentes que utilizaban o podían utilizar los pueblos para regadíos u otros aprovechamientos. No hay en ello contradicción insalvable con el argumento expuesto, ya que la ley se muestra, en cambio, totalmente respetuosa con los beneficiarios particulares efectivos, que resultaban confirmados en sus derechos. En lo que la ley no llegó a prever con suficiente claridad, la jurisprudencia había de obrar en el mismo sentido, apuntalando el principio privatizador.

Esto suponía una auténtica expoliación de los derechos consuetudinarios de los pueblos, que, lógicamente, hubieran debido consolidarse al desaparecer el dominio eminente o dominical. La pieza dispositiva capital en este sentido, una vez concluida la obra despatrimonializadora de la revolución, fue la Real Orden de 14 de marzo de 1846 que implícitamente establecía como bienes de dominio público todas las aguas que no estuvieran apropiadas por particulares ${ }^{22}$.

Aún más clara es la vigencia del principio privatizador en el caso de las aguas que, como simple adherencia del suelo comunal, fueron vendidas tras la desamortización decretada, con fecha de 1 de mayo de 1855, por el ministro de Hacienda, Pascual Madoz. Adviértase, con todo, que alli donde se dañan derechos preexistentes, ejercidos o no, es precisamente en el caso de la propiedad comunal, «imperfecta» por definición para el liberalismo, en

${ }^{21}$ La R. O. de 20 de junio de 1839 declaraba atribución de los jefes políticos, o gobernadores civiles, la competencia en las cuestiones administrativas relativas a obras y policía de riegos y otros aprovechamientos relacionados con las aguas. Mucho más importante es el contenido de la $R$. O. de 14 de marzo de 1846 por la que se declaró necesaria una autorización real para realizar cualquier empresa que tuviera relación con los ríos "sean o no navegables y flotables" (José M. Ros Brosca, Novisima legislación de aguas, Valencia, 1882, pp. 283-286).

${ }_{22}$ Fermín Abella, Manual de la legislación de aguas, expropiación y colonias agricolas, Madrid, 1874, pp. 149-151. 
tanto que difusa. $\mathrm{Y}$ es que, efectivamente, frente a la vieja propiedad compartida y solidaria, por consiguiente «imperfecta», se prefirió la concesión cuasipropietaria individual, absoluta, perpetua y alienable, es decir, "perfecta».

Todo el significado de la actitud liberal ante las aguas, y en general ante los recursos naturales, queda reflejado en lo que se refiere a las aguas corrientes. Por ello, este aspecto del dominio de las aguas públicas, y la materia complementaria de la autorización de su aprovechamiento, fue el que mayores problemas causó a los legisladores. De ahí que el número de disposiciones al respecto, con frecuencia reducidas a corregir o ampliar otras anteriores, sea muy elevado. Me limitaré a exponer y tratar de valorar muy sumariamente la regulación jurídica del régimen de concesiones, la cuestión central en este asunto.

Con las limitaciones a las que me acabo de referir, la reglamentación de ese régimen confirma el carácter privatizador de la legislación. Es de advertir, en primer lugar, que las concesiones eran gratuitas, al tiempo que se acompañaban de auténticos privilegios fiscales: la exención absoluta de contribución durante los diez primeros años para las rentas de los capitales invertidos en nuevos regadíos, y también para el aumento de valor de las tierras irrigadas, por un lado, y la exención de la mitad de la contribución imputable a los establecimientos industriales que se sirvieran de energía hidráulica, igualmente durante los diez primeros años, por otro lado ${ }^{23}$. Aún se habían de ampliar esas ventajas: las industrias que emplearan el agua como fuerza motriz fueron declaradas absolutamente libres de impuestos por la Ley de Aguas de 3 de agosto de 1866, también durante los diez años siguientes a su instalación. Estas ventajas fueron suspendidas en $1892^{24}$.

Por lo que hace al régimen de concesiones, se otorgaban sin límite de tiempo ${ }^{25}$, es decir, de forma perpetua. Desde este punto de vista, la seguridad jurídica del concesionario le hace igual o similar al propietario. Otras disposiciones posteriores mantienen la perpetuidad de las concesiones para fines agrícolas ${ }^{26}$, con la salvedad de las concesiones a sociedades o empresas para regar tierras ajenas, en cuyo caso se fija un plazo de noventa y nueve años, e industriales ${ }^{27}$.

${ }^{23}$ Ley de 24 de junio de 1849. F. GaLÁN, op. cit., p. 39, nota 1.

${ }^{24}$ Sebastián Martín-Retortillo, La Ley de Aguas de 1866. Antecedentes y elaboración, Madrid, 1963, p. 900; Angel Carmona Hernández, Manual de aguas. Legislación, jurisprudencia y doctrina, Barcelona, 1966, p. 139.

${ }^{25}$ Desde la promulgación de la $\mathrm{R}$. $\mathrm{O}$. de 14 de marzo de 1846.

${ }^{26}$ Real Decreto de 29 de abril de 1860 (C. FRANQUET Y BERTRÁn, op. cit., pp. 327337; F. AbElla, op. cit., pp. 151-156). Ley de canales y pantanos de riego de 20 de febrero de 1870 (J. M. Ros Biosca, op. cit., pp. 336-352). También el artículo 188 de la Ley de 13 de junio de 1879.

${ }^{27}$ Leyes de aguas de 3 de agosto de 1866 (art. 270) y de 13 de junio de 1879 (art. 221). La perpetuidad de la duración ha sido alterada por el Decreto de 14 de junio de 1921 (Gaceta de Madrid, 15 de junio de 1821). 
Justamente por la escasez de agua, sin embargo, se imponen una serie de requisitos que restringen notablemente la libertad de acción del concesionario y le distinguen del propietario. Todos ellos están orientados a asegurar el aprovechamiento inmediato y continuo de la concesión. El beneficiario, efectivamente, debía hacer efectivo el aprovechamiento antes de cumplirse seis meses de la autorización, y no podía cesar en él durante un año o más, en el caso de existir nuevo solicitante, o bien durante dos años o más, en la circunstancia de no existir persona interesada. La vulneración de alguna de estas exigencias suponía, por Real Orden de 21 de agosto de 1849, la caducidad de la concesión ${ }^{28}$.

El objetivo central de la legislación moderna en materia de aguas no era otro que el de promover la expansión de los usos productivos, para lo cual se reservaban, por lo menos nominalmente, amplias facultades a la Administración. La gratuidad y, sobre todo, la perpetuidad de la concesión confieren al concesionario una seguridad jurídica idéntica a la del propietario, mientras que el tratamiento fiscal privilegiado fomenta y refuerza el uso privado del agua. En cambio, la falta de libertad de acción le aleja de esa condición, aunque no -entiendo- de forma muy importante. El reconocimiento de que los aprovechamientos hidráulicos pueden ser objeto de arrendamiento, formulado en el Decreto de 15 de marzo de 1946, refuerza esta valoración ${ }^{29}$.

Un segundo paso en la vía de la transformación del régimen de uso del agua, desarrollado más modernamente, ha sido el de recortar la duración de las autorizaciones, lo que resultaba imperativamente de la necesidad de flexibilizar su gestión a la vista de los nuevos requerimientos de la moderna tecnología. En esto, las leyes españolas siguen muy tímidamente un camino que todos los países han debido emprender, más tarde o más temprano, a raíz de su creciente demanda y su consiguiente escasez ${ }^{30}$.

El conjunto de principios de orientación privatizadora, que reforzaba el dominio particular de las aguas privadas o bien de las públicas otorgadas por concesión, formaba una enmarañada serie de leyes, decretos, órdenes y preceptos que, en muchas cuestiones, presentaba lagunas y debía completarse recurriendo a las costumbres locales. A satisfacer la necesidad de clarificación y consolidación de la legislación revolucionaria sería dedicada la tarea de la codificación de aguas ${ }^{31}$, cuyo proceso formativo ha sido estudiado y documentado por Martín-Retortillo en una obra ya citada.

\footnotetext{
${ }^{28}$ F. GALAN, op. cit., pp. 57-58, nota 3; J. M.- Ros BrosCA, op. cit., pp. 287-289.

29 A. Carmona Hernández, op. cit., p. 139.

30 Ludwik Teclafr, Respuestas juridicas e institucionales al aumento de la demanda de agua, Roma, 1979.

${ }_{31}$ Francisco Romanf y Puigdengoras, Ensayo sobre codificación de aguas, Barcelona, 1866.
} 
Expuestas ya las más destacadas características del régimen de concesiones, resta una segunda gran cuestión en lo que se relaciona con las aguas declaradas de dominio público, el problema de las potestades de la Administración. En este punto sí debe reconocerse que no se satisfacían los requisitos de la plena propiedad, por lo menos tal como es entendida por el derecho romano. En efecto, del ius utendi et abutendi que la constituye, el Estado cede solamente el ius utendi y reserva a la Administración la posibilidad de ejercer el ius abutendi. Tal como resultó diseñado el conjunto de la normativa moderna de aguas, el control de los resortes de la Administración se convirtió en un eficaz instrumento de poder político.

La ley reservaba a la Administración, en palabras de un especialista,

«una amplísima competencia en materia de aguas, y singularmente la facultad de decretar e imponer las servidumbres legales, autorizar todos los aprovechamientos destinados a empresas de interés público o privado, otorgar la autorización para los aprovechamientos de riegos que requieran presas u otras obras permanentes, autorizar o conceder los aprovechamientos para molinos u otros artefactos, ejercer todas las facultades sobre policía de las aguas y otras varias, constantemente ampliadas por las disposiciones posteriores» ${ }^{32}$.

De muy especial importancia es la facultad de decidir, sin sujeción a regla o criterio alguno conocido, qué empresa o particular pretende una concesión de «mayor utilidad» cuando dos o más solicitantes concurren sobre un mismo caudal y para un mismo aprovechamiento. No menos valioso es el poder de declarar de utilidad pública un aprovechamiento solicitado que resulte incompatible con otro ya existente, puesto que esta consideración permite, previa indemnización, la expropiación forzosa. Un último aspecto que conviene destacar es que el reglamento sobre la aplicación y procedimientos de las disposiciones administrativas, previsto explícitamente en las dos versiones de la Ley de Aguas (1866 y 1879), no llegó a confeccionarse.

De todos modos, el abuso no estaba, desde luego, en la ley, sino en el comportamiento de la Administración excediéndose en el uso de sus funciones. El problema, finalmente, se circunscribe al hecho de que, frente al abuso del poder administrativo, se carecía de garantías o de medios de protección, como hubiera sido la publicidad motivada de las decisiones y, sobre todo, la posibilidad de revisión por un tribunal u organismo imparcial distinto de la Administración.

${ }^{32}$ L. Jordana de Pozas, op. cit., p. 25. 
Llegados a este punto, no parecerá excesivo afirmar que el control del agua por parte de la Administración constituyó un instrumento de dominio político de primera magnitud. No es fácil encontrar pruebas, pero sí testimonios contemporáneos.

«La ley de 3 de agosto de 1866 — consigna una publicación de gran tirada, desprovista de toda intención política-, (...) puso en manos de los gobernadores y de los ministros una gran parte de la propiedad privada, la cual ha servido con gran frecuencia en las luchas políticas de instrumento de opresión en las regiones de España en las que el riego es el principal elemento de riqueza. Es muy grave y muy peligroso mezclar, como lo hace la ley, las funciones políticas que desempeñan los gobernadores y sus superiores gerárquicos (sic), con las administrativas de policía de las aguas y concesiones de los aprovechamientos especiales de las públicas y con las esencialmente judiciales de resolver los expedientes sobre servidumbres de acueducto, estribo, etc. De temer es que los actos judiciales de los gobernadores se inspiren a veces más en las pasiones que despiertan las luchas polí. ticas que en el espíritu del precepto legal» ${ }^{33}$.

Especialmente en las regiones en que, por la escasez de los abastecimientos en relación con la demanda, el valor económico del agua era elevado, este recurso terminó siendo una de las claves del establecimiento de formas de dominio caciquiles que adulteraban el regular funcionamiento de los regímenes políticos basados en el sufragio. En definitiva, un mecanismo de poder político de primera magnitud.

La legislación despatrimonializadora que resultó de la revolución liberal, y la labor de codificación que la consolidó, no sólo alteraron el sistema legal de las aguas, sino también el juego de los poderes y fuerzas internas de la sociedad alrededor de este recurso. Tales cambios se tradujeron, como más arriba se ha indicado, en un fuerte incremento de las facultades de la Administración, sin sujeción suficiente a normas que garantizaran el derecho de los administrados. Pero alteraron, asimismo, de un modo sin duda muy importante, la estructura interna de las comunidades de regantes y, por ello, el equilibrio del sistema de relaciones tradicionales en las microsociedades que se hallaban constituidas alrededor del empleo agrícola del agua.

Las leyes liberales incluyeron, en efecto, un conjunto de disposiciones que coincidian en imponer a todas.las entidades que agrupaban a los regantes un modelo organizativo único. La base de este nuevo modelo se halla reco-

${ }^{3}$ Diccionario Enciclopédico Hispano-Americano, Barcelona, 1887, vol. I, p. 647. 
gida con claridad meridiana en la Ley de 13 de junio de 1879 , a través de sus artículos $235 \mathrm{y}$, sobre todo, $239^{34}$. «Se reunirán en junta general —dice la Ley_, y decidirá la mayoría de los asistentes, computados los votos por la propiedad que cada uno represente.» Este principio se venía repitiendo machaconamente en todas las leyes que trataron del tema desde 1836-1838.

Con ello se daba fin al principio prácticamente universal de la antigua organización de las asociaciones, pese a la multiplicidad de sus formas, de que cada individuo - herederos se les llamará con frecuencia- disponía de un voto. Herencia de la antigua propiedad comunal, la participación igual de todos en las deliberaciones respondía a que el acceso al agua, como a la tierra, se efectuaba a través de la pertenencia al grupo, por razón de vecindad ${ }^{35}$. La imposición del nuevo modelo organizativo venía a reforzar, probablemente, la capacidad de decisión de las comunidades de regantes. Pero también venía a recrudecer el crecimiento tendencial de la desigualdad en la sociedad rural. Al mismo resultado había de contribuir, sin duda, en una proporción imposible de determinar, la reducción de los ingresos municipales que, para muchos pueblos, supuso el fin de la explotación de las aguas como bienes patrimoniales o de propios.

\section{Conclusión}

La legislación despatrimonializadora revolucionaria estaba inspirada en la voluntad de proceder a la movilización de los recursos naturales sobre la base de una orientación claramente productivista. Su objetivo principal fue el de valorizar en la mayor medida posible una fuente de riqueza que el antiguo régimen patrimonial mantenía en buena parte estéril. Rompió todas las rigideces e inflexibilidades del antiguo sistema hidráulico, desde el dominio patrimonial feudal hasta los derechos excluyentes de los vecinos y los aprovechamientos comunales. Al eliminar las cargas feudales que sobre ella pesaban, determinó una fuerte caída de los precios del agua.

Se trató de fortalecer al máximo la propiedad privada del agua y, en la međida que ésta pudiera obstaculizar los aprovechamientos, se tendió a imponer el régimen de concesiones cuasipropietarias. Se acompañaron, todavia, estas medidas de amplias facilidades y privilegios fiscales. Ya las disposiciones de exención del pago de diezmos en las tierras de nueva irrigación, dictadas por Fernando VII, habían producido «entonces grandes resultados» ${ }^{36}$. Las

34 Melchor de Palau, Ley de Aguas de 13 de junio de 1879, con comentarios, referencias y notas criticas, Barcelona, 1879 , pp. 84 y 96.

${ }^{35}$ Aunque, a veces, con claras interferencias de carácter estamental. Véanse antiguas ordenanzas de riegos en Jaubert DE PASSA, Canales de riego de Cataluña y reino de Valencia. Traducida y adicionada por Juan Fiol, Valencia, 1844.

${ }^{36}$ F. GaláN, op. cit., p. 38. 
exenciones contributivas otorgadas por los gobiernos liberales contribuyeron en gran medida, asimismo, a ello. Los avances tecnológicos en los medios de captación de aguas y en los sistemas de irrigación ${ }^{37}$ terminaron de facilitar la extensión de la superficie regada. En las regiones en las que el tema ha sido estudiado, como en Valencia ${ }^{38}$, el balance es muy positivo.

En lo que se refiere a la industria debe consignarse otro tanto. Es cierto que no faltan muestras de que muchos empresarios se servían, en las décadas de 1870 y 1880 , de concesiones muy antiguas. Pero no es menos cierto que la forma de utilizar estos viejos derechos era absolutamente nueva. Sólo la introducción de la moderna turbina, en sustitución de las antiguas ruedas, había hecho posible para entonces la renovada utilización de la energía hidráulica en los sectores más modernos de la industria. No es casualidad, evidentemente, que la industria algodonera catalana tendiera de nuevo a instalarse en las orillas de los ríos, a partir de la década de 1860-1870, y a escapar del litoral, donde se había ido concentrando en las décadas inmediatamente anteriores para reducir los costes del carbón inglés que se utilizaba como combustible para las máquinas de vapor ${ }^{39}$. Pero, aun así, antes de esa recuperación del empleo del agua como fuerza motriz por la tecnología moderna, la base de la producción industrial del país seguía basándose en los molinos hidráulicos.

\section{Motores y potencia de la industria fabril el año $1862^{40}$}

\begin{tabular}{|c|c|c|}
\hline & Motores & $\begin{array}{l}\text { Fuerza util } \\
\text { (caballos } \\
\text { de vapor) }\end{array}$ \\
\hline $\begin{array}{lllllllllll}\text { Molinos hidráulicos } & \ldots & \ldots & \ldots & \ldots & \ldots & \ldots & \ldots & \ldots & \ldots \\
\text { Molinos de viento } & \ldots & \ldots & \ldots & \ldots & \ldots & \ldots & \ldots & \ldots & \ldots & \ldots \\
\text { Máquinas de vapor } & \ldots & \ldots & \ldots & \ldots & \ldots & \ldots & \ldots & \ldots & \ldots & \ldots\end{array}$ & $\begin{array}{r}46.793 \\
1.346 \\
828\end{array}$ & $\begin{array}{l}104.363 \\
595,2 \\
13.262\end{array}$ \\
\hline $\begin{array}{llllllllll}\text { TOtaL } & \ldots & \ldots & \ldots & \ldots & \ldots & \ldots & \ldots & \ldots & \ldots\end{array}$ & 48.967 & $118.220,2$ \\
\hline
\end{tabular}

El cuadro adjunto da cuenta de ello: la potencia generada por los modernos motores de vapor representaba, teóricamente, sólo poco más del 10

${ }^{37}$ Andrés Llaukadó, Tratado de aguas y riegos, Madrid, 1884, pp. 240-252.

${ }^{38}$ Antonio López-Gómez, "Nuevos riegos en Valencia en el siglo xIX y comienzos del xx", en Jordi Nabal y Gabriel Tortella (eds.), Agricultura, comercio colonial y crecimiento económico en la España contemporánea, Barcelona, 1974, páginas 188-205.

${ }^{39}$ Jordi NADAL, El fracaso de la revolución industrial en España, 1814-1913, Barcelona, 1975, pp. 198-201.

"Francisco Javier DE BoNa, "Industria fabril de España. Agentes dinámicos", en Las Antillas, núms. 14-19 (25 de junio a 10 de septiembre de 1867). 
por 100 del total. Es muy posible, ciertamente, que el balance energético real difiera mucho de estas cifras, por la distinta frecuencia del empleo de los varios tipos de motores. Pero, aun así, debe reconocerse que el grueso de la actividad industrial se centraba en la explotación de la energía hidráulica. Desde entonces, esto no haría sino progresar, primero por la ya mencionada introducción de las modernas turbinas y, no mucho más tarde, por el desarrollo de la hidroelectricidad.

El sentido global del conjunto de las leyes despatrimonializadoras del agua, como también el de las disposiciones revolucionarias en relación con la tierra o con el subsuelo, consiste en eliminar las dificultades que el régimen tradicional imponía a la utilización. El objetivo de los gobernantes liberales queda espléndidamente condensado en la afirmación, atribuida al mismo Mendizábal, de que «España no será rica mientras los ríos desemboquen en el mar» ${ }^{41}$.

"Gustavo lA IGLesia, Legislación de aguas, Madrid, 1920, p. 34. 